\title{
Greater efficacy of chemotherapy plus bevacizumab compared to chemo- and targeted therapy alone on non-small cell lung cancer patients with brain metastasis
}

\author{
Ning Tang ${ }^{1}$, Jun Guo ${ }^{2}$, Qianqian Zhang ${ }^{1}$, Yali Wang', Zhehai Wang ${ }^{2}$ \\ ${ }^{1}$ School of Medicine and Life Sciences, University of Jinan-Shandong Academy of Medical Sciences, Jinan, Shandong, China \\ ${ }^{2}$ Department of Shandong Cancer Hospital and Institute, Jinan, Shandong, China \\ Correspondence to: Zhehai Wang, e-mail: 731060946@qq.com
}

Keywords: non-small cell lung cancer, brain metastases, chemotherapy, tyrosine kinase inhibitors, epidermal growth factor receptor

Received: August 11, 2015

Accepted: October 14, 2015

Published: October 20, 2015

\section{ABSTRACT}

Control of non-small-cell lung cancer (NSCLC) with brain metastasis is clinically challenging. This study retrospectively evaluated the efficacy of different adjuvant therapies for $\mathbf{7 7 6}$ cases of advanced NSCLCs with brain metastasis who treated with chemotherapy, chemotherapy plus bevacizumab, tyrosine kinase inhibitor (TKI) alone, or supportive care. The median progression-free survival (MPFS) and median overall survival (mOS) of patients treated with chemotherapy plus bevacizumab were 8.5 and 10.5 months, respectively, which were better than those of patients treated with other three therapies $(P<0.01)$. For patients with EGFR-mutated NSCLC, the efficacy of TKI treatment was not statistically better than that of chemotherapy plus bevacizumab but was significantly better than that of other therapies. Moreover, for patients with EGFR wild-type NSCLC, the MPFS and mOS after chemotherapy plus bevacizumab were greater than those with other two therapies $(P<0.01)$. The local response rate (RR)and disease control rate (DCR)with regimen including pemetrexed were greater than those with regimen including paclitaxel $(P<0.05)$. Chemotherapy plus bevacizumab was more effective for NSCLC patients with brain metastasis. Further studies will investigate the benefit of TKI alone for patients with EGFR-mutated. For patients with EGFR wild-type, chemotherapy plus bevacizumab did improve PFS and OS. Furthermore, regimens including pemetrexed led to a greater RR.

\section{INTRODUCTION}

Lung cancer is the leading cause of cancer-related deaths in the world [1] and non-small cell lung cancer (NSCLC) accounts for approximately $80 \%$ of all lung cancer cases [1]. NSCLC is usually diagnosed at the advanced stages of disease, and brain metastasis is a common complication in NSCLC patients, with more than $10 \%$ of NSCLC patients presenting with brain metastases at their first hospital visit $[2,3]$ and $30 \%-40 \%$ of NSCLC patients developing brain metastasis during the course of the disease [4]. The standard treatment protocol for patients with multiple metastases is whole brain radiotherapy (WBRT) [5] and steriotactic radiosurgery (SRS) used to treat solitary or oligo-metastatic disease that contains the following techniques: gamma knife, threedimensional conformal radiation therapy (3DCRT), and/or intensity modulation radiated therapy (IMRT) [6-9]. For patients with multiple cerebral lesions, the prognosis is still poor; the median overall survival $(\mathrm{mOS})$ was reported to be only 4-6 months after radiotherapy $[10,11]$ or only approximately 1 month without treatment. Furthermore, the quality of life of these patients is also very poor [5]. Thus, more effective treatment regimens or strategies to control NSCLC with brain metastasis are urgently needed.

To date, the best optimal chemotherapy regimens for NSCLC patients with brain metastases are still deba Table and sometimes are controversial, although platinum compounds are still basically the first-line NSCLC chemotherapy in the clinic. Recent studies showed the effectiveness of pemetrexed treatment in NSCLC patients with brain metastasis [12-14], and molecular targeted drugs have offered new hope to these patients [15]. Bevacizumab, the most widely used drug in 
anti-angiogenic therapy, has also been shown to improve response rates, progression-free survival (PFS), and OS compared to chemotherapy alone [16-18]. However, with the fear of tumor-related intracranial hemorrhage (ICH) [19], the use of bevacizumab to treat NSCLC patients has remained fairly rare, except in one study reported by Socinskiet al. [15] who suggested that addition of bevacizumab to various chemotherapy regimens or erlotinib for treating NSCLC patients with brain metastases is safe. However, the efficacy of this strategy remains to be confirmed. For NSCLC patients, targeted therapy is progressing rapidly [20-30]. One example is the targeting of mutations of epidermal growth factor receptor (EGFR). Several randomized, open-label, phase III clinical trials have compared tyrosine kinase inhibitors (TKIs) with the routine chemotherapy, and the data suggest that the response rate (RR) and PFS of patients with EGFR-mutated NSCLC who receive EGFR-TKIs as a first-line treatment are significantly greater than those of patients who receive chemotherapy, although the OS did not differ significantly between these two treatments [20-30]. In addition, NSCLC patients with brain metastasis were excluded from these studies [20-30]. Patients with EGFR-mutated NSCLC do not usually receive TKI treatment in China due to economic or other reasons. Thus, in this study, we compared the effectiveness of different treatment regimens in NSCLC patients with brain metastasis using a retrospective setting to provide valuable information for future clinical treatment of NSCLC patients with brain metastasis.

\section{RESULTS}

\section{Patient characteristics}

For the 776 patients included in this study, the median age was 58 years;423 were male and 353 female. All patients had brain metastasis and $37 \%$ also had pulmonary metastasis, $24 \%$ had ossary metastasis, and 7\% had hepatic metastasis. These patients were treated with chemotherapy alone, chemotherapy plus bevacizumab, TKIs alone, or supportive care. However, all patients, except 61 who received only supportive care, had received concurrent radiotherapy (WBRT or SRS). The characteristics of these patients are shown in Table 1, and no significant differences were observed between the four treatment groups.

\section{Association of treatment selections with patient survival}

PFS and OS data stratified by the different treatments were analyzed using Kaplan-Meier curves and the log-rank test (Figure 1). Specifically, the mPFS of all 776 patients was 5.5 months (95\% confidence interval [CI]:5.1-5.8 months), and the mPFS times after chemotherapy alone, chemotherapy plus bevacizumab,
TKIs alone, and supportive care were 5.0 months (95\% CI: 4.7-5.2 months), 8.5 months (95\% CI:7.7-9.3 months), 8.0 months (95\% CI:6.8-9.1 months), and 1.5 months (95\% CI:1.3-1.6 months), respectively. The mPFS after chemotherapy plus bevacizumab was significantly greater than those of the other three treatment groups $(P<0.05)$, including even the TKI treatment group $(P=0.024)$.

The mOS of all 776 patients was 7.7 months (95\% CI:7.4-7.9 months), and the mOS times after chemotherapy alone, chemotherapy plus bevacizumab, TKIs alone, and supportive care were 7.3 (95\% CI:6.9-7.6), 10.5 (95\% CI:9.7-11.3), $10.3 \quad$ (95\% CI:9.0-11.5), and 3.0 months (95\% CI:2.8-3.2 months), respectively. The mOS after chemotherapy plus bevacizumab was significantly greater than that after chemotherapy alone and after supportive care $(P<0.01)$, but not statistically different from that with the TKI treatment $(P=0.836)$.

\section{Association of different treatments with survival of patients with EGFR mutated NSCLC}

PFS and OS data for the 416 patients with EGFR mutated NSCLC were stratified by the different treatments for analysis with Kaplan-Meier curves and the log-rank test (Figure 2). Specifically, the mPFS of these 416 patients was 6.5 months (95\% CI: 6.1-6.8 months), whereas the mPFS times after chemotherapy alone, chemotherapy plus bevacizumab, TKIs alone, and supportive care were 6.0 (95\% CI: 5.6-6.3), 7.5 (95\% CI:6.8-8.2), 8.0 (95\% CI:6.8-9.1), and 1.0 month(s) (95\% CI:0.8-1.2), respectively. The mPFS after TKI treatment alone was significantly greater than that after chemotherapy alone and after supportive care $(P<0.01)$, but not statistically different from that after chemotherapy plus bevacizumab $(P=0.411)$.

The mOS of these 416 patients was 8.3 months (95\% CI:7.9-8.7), whereas the mOS after chemotherapy alone, chemotherapy plus bevacizumab, TKIs alone, and supportive care was 7.7 (95\% CI:7.3-8.0), 9.3 (95\% CI: 8.5-10.1), 10.3 (95\% CI:9.0-11.5), and 2.9 months (95\% CI:2.6-3.1 months), respectively. The mOS after TKI treatment alone was significantly greater than that after chemotherapy alone and after supportive care $(P<0.01)$, but was not statistically different from that after chemotherapy plus bevacizumab $(P=0.130)$.

\section{Association of different treatments with survival of patients with wild type EGFR NSCLC}

The PFS and OS data for the 360 patients with EGFR wild type NSCLC were stratified by the different treatments for analysis with Kaplan-Meier curves and the log-rank test (Figure 3). Specifically, the mPFS of these 360 patients was 4.5 months (95\% CI:4.2-4.8 months), whereas the mPFS after chemotherapy alone, chemotherapy plus bevacizumab, and supportive care 
Table 1: Characteristics of patients and treatment selections [n(\%)]

\begin{tabular}{|c|c|c|c|c|c|c|}
\hline Characteristics (\%) & $\begin{array}{c}\text { Overall } \\
(N=776)\end{array}$ & $\begin{array}{c}\text { Chemotherapy } \\
\text { alone } \\
(N=523)\end{array}$ & $\begin{array}{c}\text { Chemotherapy } \\
\text { + bevacizumab } \\
(N=117)\end{array}$ & $\begin{array}{l}\text { TKIs alone } \\
\quad(N=75)\end{array}$ & $\begin{array}{c}\text { Supportive } \\
\text { care } \\
(N=61)\end{array}$ & $P$ \\
\hline \multicolumn{7}{|l|}{ Age (years) } \\
\hline$>50$ & $546(70.4)$ & $376(71.9)$ & $65(55.6)$ & $53(70.7)$ & $52(85.2)$ & \\
\hline$\geq 50$ & $230(29.6)$ & $147(28.1)$ & $52(44.4)$ & $22(29.3)$ & $9(14.8)$ & $>0.05$ \\
\hline \multicolumn{7}{|l|}{ Sex } \\
\hline male & $423(54.5)$ & 292(55.9) & $53(45.3)$ & $38(50.7)$ & $40(65.6)$ & \\
\hline female & $353(45.5)$ & $231(44.2)$ & $64(54.7)$ & $37(49.3)$ & $21(34.4)$ & $>0.05$ \\
\hline \multicolumn{7}{|l|}{ ECOG } \\
\hline $0-2$ & $719(92.7)$ & 498(95.2) & $112(95.7)$ & $69(92.0)$ & $40(65.6)$ & \\
\hline$\geq 3$ & $57(7.3)$ & $25(4.8)$ & $5(4.3)$ & $6(8.0)$ & $21(34.4)$ & $>0.05$ \\
\hline \multicolumn{7}{|l|}{ Histologic type } \\
\hline $\mathrm{AC}$ & $726(93.6)$ & $484(92.5)$ & $110(94.0)$ & $74(98.7)$ & $58(95.1)$ & \\
\hline $\mathrm{SCC}$ & $50(6.4)$ & $39(7.5)$ & $7(6.0)$ & $1(1.3)$ & $3(4.9)$ & $>0.05$ \\
\hline \multicolumn{7}{|l|}{ EGFR } \\
\hline mutation & $416(53.6)$ & $249(47.6)$ & $70(59.8)$ & $75(100)$ & $22(36.1)$ & \\
\hline wild-type & $360(46.4)$ & $274(52.4)$ & $47(40.2)$ & 0 & $39(63.9)$ & \\
\hline \multicolumn{7}{|l|}{$\begin{array}{l}\text { Other sites of } \\
\text { metastases }\end{array}$} \\
\hline lung & $289(37.2)$ & $190(36.3)$ & $47(40.2)$ & $38(50.7)$ & $14(23.0)$ & \\
\hline bone & $188(24.2)$ & $117(22.4)$ & $35(29.9)$ & $26(34.7)$ & $10(16.4)$ & \\
\hline liver & $53(6.8)$ & $36(6.8)$ & $6(5.1)$ & $6(8.0)$ & $5(8.2)$ & \\
\hline adrenal gland & $28(3.6)$ & $20(3.8)$ & $3(2.6)$ & $2(2.7)$ & $3(4.9)$ & \\
\hline pleura & $25(3.2)$ & $16(3.1)$ & $7(6.0)$ & 0 & $2(3.3)$ & \\
\hline kidney & $20(2.6)$ & $11(2.1)$ & $3(2.6)$ & $3(4.0)$ & $3(4.9)$ & \\
\hline \multicolumn{7}{|l|}{$\begin{array}{l}\text { Single lesion of } \\
\text { the CNS }\end{array}$} \\
\hline Yes & $203(26.2)$ & $144(27.5)$ & $30(25.6)$ & $23(30.7)$ & $6(9.8)$ & \\
\hline No & $573(73.8)$ & $379(72.5)$ & $87(74.4)$ & $52(69.3)$ & $55(90.2)$ & $>0.05$ \\
\hline \multicolumn{7}{|l|}{ Chemotherapeutic regimen } \\
\hline Taxol & $344(44.3)$ & $286(54.7)$ & $58(49.6)$ & & & \\
\hline Pemetrexed & $278(35.8)$ & $220(42.1)$ & $58(49.6)$ & & & \\
\hline Gemcitabine & $16(2.1)$ & $15(2.9)$ & $1(0.1)$ & & & \\
\hline Other & $2(0.3)$ & $2(0.4)$ & 0 & & & \\
\hline
\end{tabular}




\begin{tabular}{|l|l|l|l|l|l|l|}
\hline Response & & & & & & \\
\hline CR+PR & $228(29.4)$ & $156(29.8)$ & $46(39.3)$ & $26(34.7)$ & 0 & \\
\hline SD & $266(34.3)$ & $184(35.2)$ & $42(35.9)$ & $26(34.7)$ & $14(23.0)$ & \\
\hline DCR & $494(63.7)$ & $340(65.0)$ & $88(75.2)$ & $52(69.3)$ & $14(23.0)$ & \\
\hline PD & $282(36.3)$ & $183(35.0)$ & $29(24.8)$ & $23(30.7)$ & $47(77.0)$ & \\
\hline
\end{tabular}

Abbreviations: EGFR, epidermal growth factor receptor; ECOG, Eastern Cooperative Oncology Group; CR, complete response; PR, partial response; SD, stable disease; DCR, disease control rate; PD, progression of disease; TKIs, tyrosine kinase inhibitors; AC, adenocarcinoma; SCC, squamous cell carcinoma

was 4.5 (95\% CI:4.2-4.8), 9.0 (95\% CI: 8.4-9.5), and 1.5 months (95\% CI:1.3-1.6 months), respectively. The mPFS after chemotherapy plus bevacizumab was significantly greater than that after chemotherapy alone and after supportive care $(P<0.01)$.

The mOS of these 416 patients was 6.3 months (95\% CI: 5.7-6.8 months), whereas the mOS after chemotherapy alone, chemotherapy plus bevacizumab, and supportive care group was 6.7 (95\% CI: $6.2-7.1)$, 10.7 (95\% CI: $10.3-11.1)$, and 3.2 months $(95 \% \mathrm{CI}$ : 3.0-3.4 months), respectively. The mOS after chemotherapy plus bevacizumab was significantly greater than that after chemotherapy alone and after supportive care $(P<0.01)$.

\section{Association between different cytotoxic drugs and survival in patients who received adjuvant chemotherapy}

Among the total of 776 patients, 622 patients were treated with adjuvant chemotherapy. We assessed the treatment responses for different cytotoxic drugs as the first-line treatment (Table 2). Among patients who received a pemetrexed regimen $(n=278)$ oral taxane regimen $(n=344)$, the concurrent effect on the overall response among the different cytotoxic drugs did not differ significantly $(P>0.05)$, whereas the RR and DCR for a local response to regimens including pemetrexed or taxane were significantly better than those for a regimen including paclitaxel $(P<0.05)$.

\section{Toxicity and feasibility of different therapies}

Drug toxicity was evaluated according to WHO criteria, and no grade 3/4 adverse reactions occurred among patients in all four different groups, even among the 57 patients with a performance status $\geq 3$ (Table 3 ). There was no significant differences in drug toxicity among the three treatments not including supportive care group $(P>0.05)$. Also, no cases of $\mathrm{ICH}$, hypertension, epistaxis, protenuria, or hemoptysis occurred after any treatment (Table 3).

\section{DISCUSSION}

In the current study, we assessed the effectiveness of different therapeutic regimens on PFS and OS of 776 NSCLC patients with brain metastasis. We found that
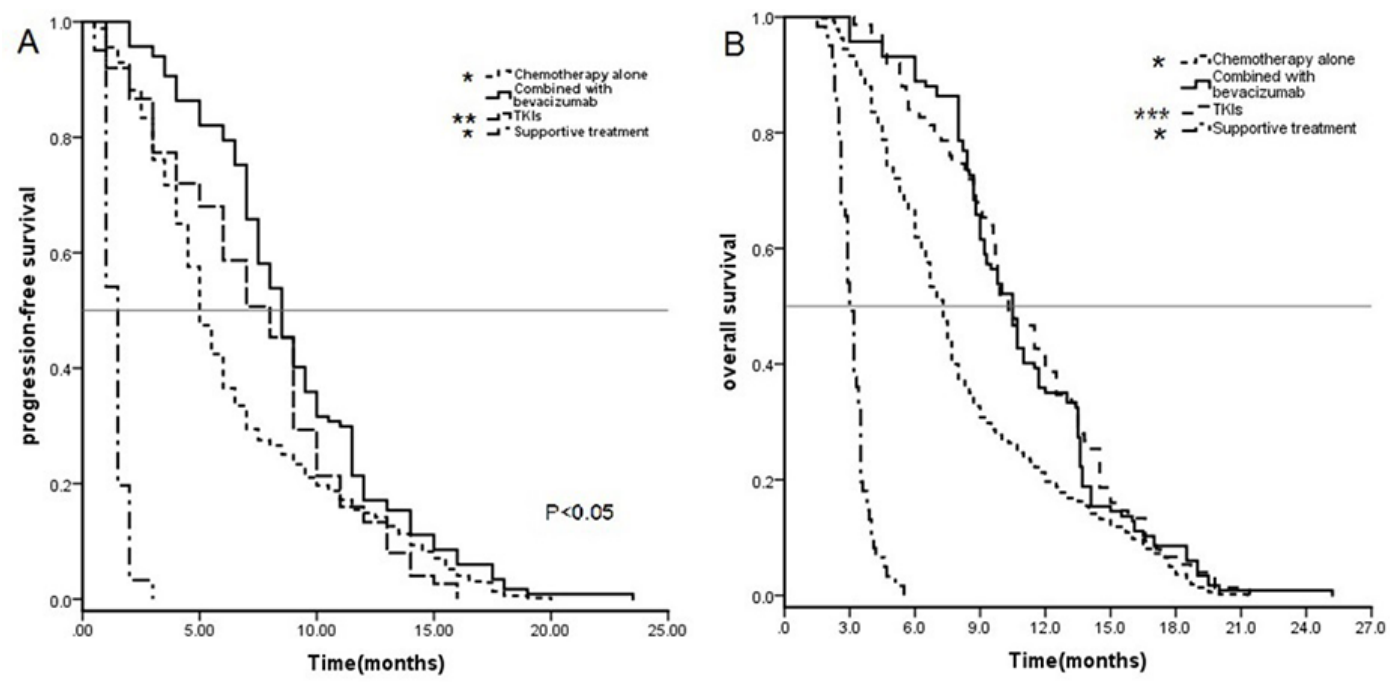

Figure 1: Kaplan-Meier curves for progression-free survival (PFS) (A) and overall survival (OS) (B) of all 776 patients. $* P<0.01$ for chemotherapy plus bevacizumab compared to chemotherapy alone; $* * P<0.05$ for chemotherapy plus bevacizumab compared to TKIs alone; $* * * P>0.05$ for chemotherapy plus bevacizumab compared to supportive care. 
chemotherapy plus bevacizumab resulted in an mPFS of 8.5 months and an mOS of 10.5 months and that these PFS and OS were significantly greater than those with chemotherapy alone or supportive care. However, the efficacy of the maintenance TKI treatment of patients with EGFR-mutated NSCLC did not differ significantly from that of chemotherapy plus bevacizumab, but was significantly better than that of chemotherapy alone or supportive care. Moreover, the mPFS and mOS after chemotherapy plus bevacizumab in patients with EGFR wild-type NSCLC were significantly better than those after chemotherapy alone or supportive care. Our current study demonstrated that chemotherapy plus bevacizumab was more effective on NSCLC patients with brain metastasis and the adverse reactions were tolerable. Further prospective studies are needed to confirm our current findings.

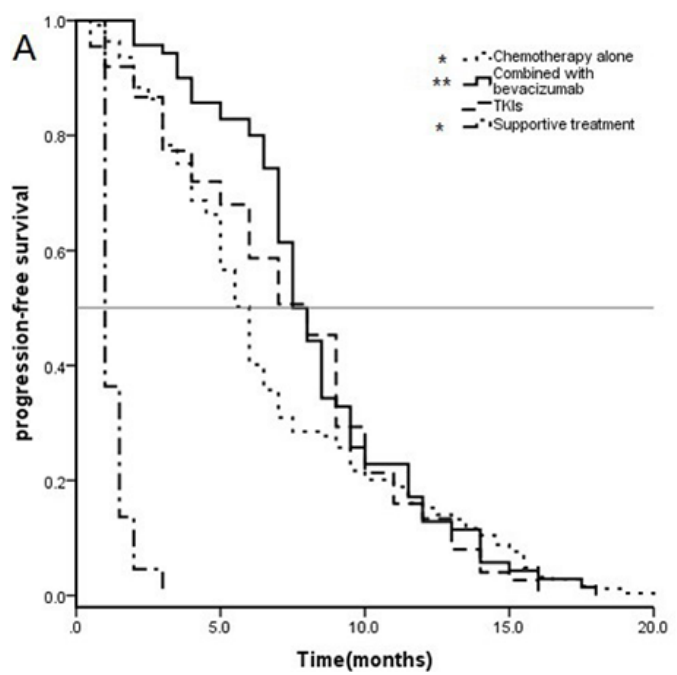

Tumor metastasis is a multiple mechanistic process by which tumor cells from a primary site invade and metastasize to a secondary site, while metastasis to the brain is even more complex. This is because tumor brain metastases have their own characteristics. Tumor metastasis to the brain can be divided into six basic steps: escape from the primary site (escape), spreading into the circulation system (dissemination), adhesion and vascular wall (attachment), penetration of the blood-brain barrier into the brain parenchyma (extravasation), brain microenvironment interactions (interaction), and growth in the brain (or secondary site) (survival and proliferation) [31]. Kienast et al. [32] established a mouse brain metastasis model by injecting tumor cells into the carotid artery and used multiphoton laser scanning microscopy to image the single steps of metastasis formation in real time. Their findings revealed that the most critical step in tumor

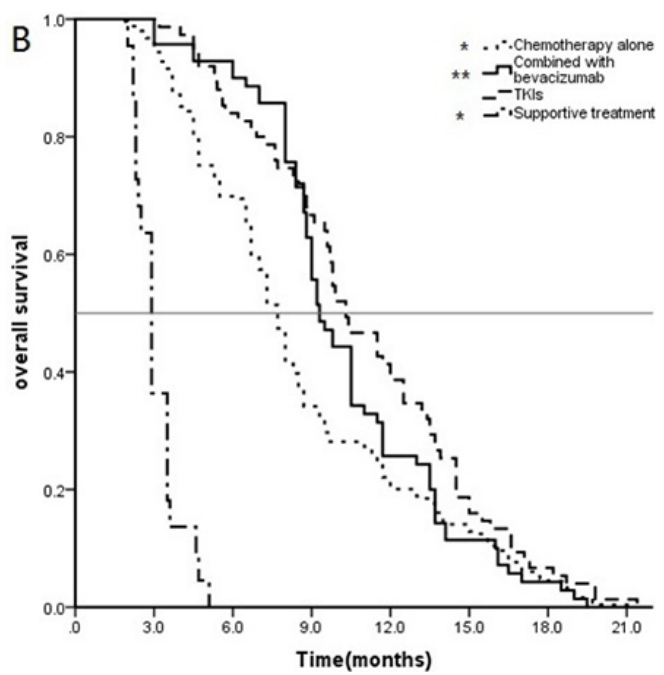

Figure 2: Kaplan-Meier estimates of (A) progression-free survival (PFS) and(B) overall survival (OS) in 416 patients with EGFR mutated NSCLC. $* P<0.05$ for chemotherapy alone versus TKI treatment alone and $* * P>0.05$ for chemotherapy plus bevacizumab versus TKI treatment alone.
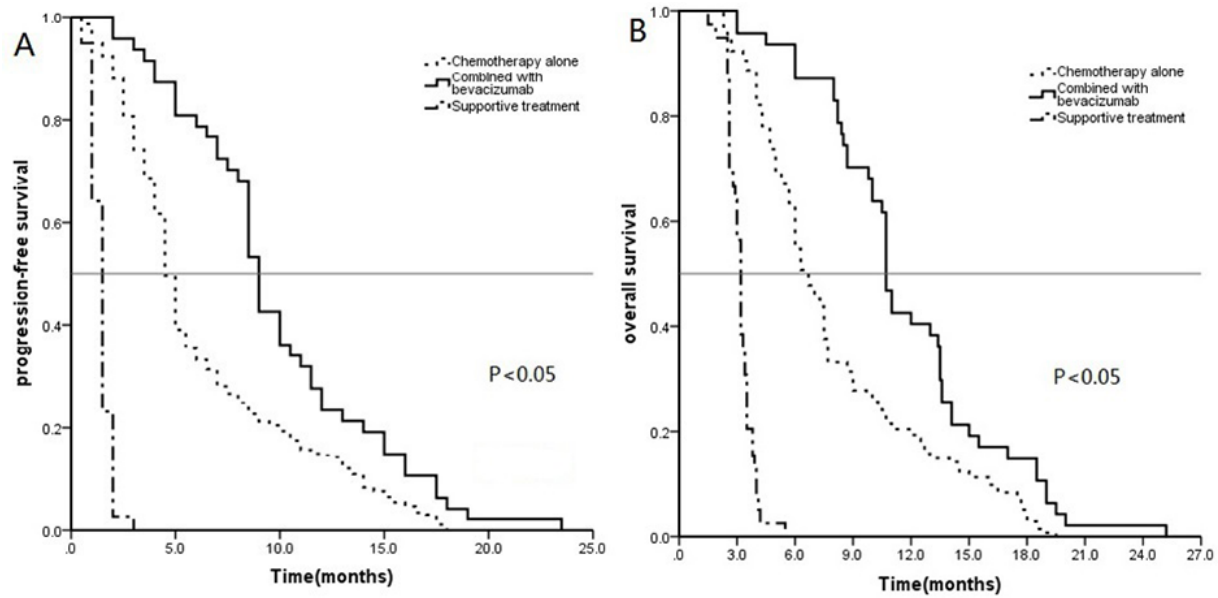

Figure 3: Kaplan-Meier curves for progression-free survival (PFS) (A) and overall survival (OS) (B) in 360 patients with EGFR wildtype NSCLC. 
Table 2: Overall and local response of NSCLC patients with brain metastasis to different cytotoxic drugs $[n(\%)]$

Response
\begin{tabular}{|l|c|c|c|}
\hline Overall & $\begin{array}{c}\text { Regimen including } \\
\text { pemetrexed }\end{array}$ & $\begin{array}{c}\text { Regimen including } \\
\text { taxane }\end{array}$ \\
\hline CR & 0 & 0 & \\
\hline PR & $91(32.7)$ & $91(26.5)$ & 0.087 \\
\hline CR + PR & $91(32.7)$ & $91(26.5)$ & 0.10 \\
\hline SD & $89(32.0)$ & $132(38.3)$ & 0.33 \\
\hline DCR & $180(64.7)$ & $223(64.8)$ & $111(35.2)$ \\
\hline PD & $98(35.3)$ & & 0.015 \\
\hline Local & & & 0.003 \\
\hline CR & $6(2.2)$ & $104(30.2)$ & 0.30 \\
\hline PR & $110(39.6)$ & $104(30.2)$ & 0.044 \\
\hline CR + PR & $116(41.8)$ & $116(33.7)$ & \\
\hline SD & $83(29.9)$ & $220(63.9)$ & $124(36.1)$ \\
\hline DCR & $199(71.6)$ & & \\
\hline PD & $79(28.4)$ & & \\
\hline
\end{tabular}

metastasis to the brain is the blockage of tumor cells in the microvessels, which allows them to effectively penetrate the vessel walls, closely adhere to perivascular cells, and form micrometastasis in the brain [32]. If tumor cells fail to undergo these four steps, they become motionless, decline, or die. Overall, only $1.0 \% \sim 2.4 \%$ of lung cancer cells injected into the carotid artery completed the metastasis process, which is lower than the $4.7 \% \sim 7.0 \%$ of melanoma cells that complete the metastasis process [32]. These results demonstrated that tumor cells exhibit different biological behaviors in these fourth key steps, i.e., the support of melanoma growth was a vascular co-option that was dependent on the existing blood vessels, and angiogenesis supported adenocarcinoma metastatic cell growth. Thus, these previous findings provided a mechanistic basis for anti-angiogenesis therapy for lung cancer metastasis to the brain.

Bevacizumab is a recombinant, humanized monoclonal antibody that directly targets vascular endothelial growth factor (VEGF) [16]. The latter regulates tumor-associated angiogenesis. Bevacizumab, combined with platinum-based doublet regimen, is a US Food and Drug Administration-approved first-line treatment for patients with unresectable, locally advanced, recurrent, or metastatic NSCLC $[16,33,34]$. In a previous phase III study reported by the Eastern Cooperative Oncology Group (ECOG), bevacizumab accession can significantly improve the OS and PFS of NSCLC patients compared to carboplatin/paclitaxel alone [16]. The results of our current study showed that chemotherapy plus bevacizumab as the first-line treatment regimen was much more effective than chemotherapy alone and comparable with TKI treatment alone. With respect to the adverse effects of this regimen, there were no grade 3-4 adverse reactions observed in patients and no adverse reactions related to bevacizumab, such as $\mathrm{ICH}$, hypertension, epistaxis, proteinuria, and hemoptysis, occurred. Thus, our finding suggests that chemotherapy plus bevacizumab as the first-line treatment had a better curative rate and tolerable adverse reactions in NSCLC patients with brain metastasis, especially in patients with EGFR wild type NSCLC.

Furthermore, previous studies have considered that the effectiveness of chemotherapy is subject to a presumed lack of effectiveness due to the blood-brain barrier [12]. Actually two reasons were behind the poor response: i) Utilization rate of drug at the site of action remains low, and ii) Intrinsic or acquired resistance to anticancer agents [35]. This may be because overexpression or mutation of drug-targeting enzymes leads to natural or acquired resistance [35]. Pemetrexed has been therefore developed to solve these problems by inhibiting at least three types of enzymes [36]. Simultaneous inhibition of these three enzymes at multiple sites could lead to improvement of drug effectiveness. Thus, use of pemetrexed could overcome intrinsic or acquired drug resistance, and previous clinical studies confirmed the broad usefulness of pemetrexed in the treatment of a variety of solid tumors [36-38]. These enzymes include dihydrofolate reductase (DHFR), thymidylate synthetase, glycinamideribonucleotide-formyl transferase [36-39]. In our current 
Table 3: Response rates and Adverse effects of each treatment [ $n(\%)]$

\begin{tabular}{|c|c|c|c|c|}
\hline & $\begin{array}{c}\text { Chemotherapy } \\
\text { alone }\end{array}$ & Chemotherapy + bevacizumab & $\begin{array}{l}\text { TKIs } \\
\text { alone }\end{array}$ & $\begin{array}{l}\text { Supportive } \\
\text { care }\end{array}$ \\
\hline \multicolumn{5}{|l|}{ Response } \\
\hline $\mathrm{CR}+\mathrm{PR}$ & $156(29.8)$ & $46(39.3)$ & $26(34.7)$ & 0 \\
\hline SD & $184(35.2)$ & $42(35.9)$ & $26(34.7)$ & $14(23.0)$ \\
\hline DCR & $340(65.0)$ & $88(75.2)$ & $52(69.3)$ & $14(23.0)$ \\
\hline PD & $183(35.0)$ & $29(24.8)$ & $23(30.7)$ & $47(77.0)$ \\
\hline \multicolumn{5}{|l|}{$\begin{array}{l}\text { Adverse reaction } \\
\text { Grade } 2\end{array}$} \\
\hline \multicolumn{5}{|l|}{ Hematological } \\
\hline Neutropenia & $210(40.2)$ & $40(34.2)$ & $26(34.7)$ & $2(3.3)$ \\
\hline Anemia & $62(11.9)$ & $13(11.1)$ & $8(10.7)$ & $2(3.3)$ \\
\hline Thrombocytopenia & $125(23.9)$ & $26(22.2)$ & $7(9.3)$ & $1(1.6)$ \\
\hline \multicolumn{5}{|l|}{ Non-hematological } \\
\hline Asthenia & $283(54.1)$ & $53(45.3)$ & $30(40.0)$ & $5(8.2)$ \\
\hline Anorexia & $260(49.7)$ & $54(46.2)$ & $32(42.7)$ & 0 \\
\hline Vomiting & $30(5.7)$ & $6(5.1)$ & $4(5.3)$ & 0 \\
\hline Diarrhea & $27(5.2)$ & $5(4.3)$ & $4(5.3)$ & $1(1.6)$ \\
\hline Constipation & $190(36.3)$ & $40(34.2)$ & $25(33.3)$ & 0 \\
\hline Rash & $29(5.5)$ & $7(6.0)$ & $6(8.0)$ & 0 \\
\hline Weight loss $\geq 3 \mathrm{~kg}$ & $39(7.5)$ & $5(4.3)$ & $3(4.0)$ & $3(4.9)$ \\
\hline
\end{tabular}

Abbreviations: CR, complete response; PR, partial response; SD, stable disease; DCR, disease control rate; PD, progression of disease; TKIs, tyrosine kinase inhibitors.

study, the RRs and DCRs for different cytotoxic drugs did not differ significantly, whereas the local RR and DCR for regimens including pemetrexed were significantly greater than those for regimens including paclitaxel. Our study included five patients with single brain lesions that showed CR after the treatment. This implies that pemetrexed was able to pass through the blood-brain barrier to reach tumor lesion. Thus, a regimen including pemetrexed may outperform the other cytotoxic drugs.

In addition, a previous phase II clinical trial showed that WBRT combined with the molecular targeted drug erlotinib improved the OS of NSCLC patients with brain metastasis, especially those with EGFR mutated NSCLC [39]. Multiple studies suggest that WBRT combined with TKIs was able to improve the control of disease progression and was well tolerated [40]. The efficiency of WBRT plus TKIs was about $70 \%$ in patients independent of EGFR status [40], which was significantly higher than that of WBRT or chemotherapy alone. Kim et al. treated 23 patients with EGFR-TKIs as the first line and showed an mPFS of 7.1 months and an mOS of 18.8 months, leading to a $82.6 \%$ control rate [41]. However, the use of EGFR-TKIs as a first-line treatment remains controversial
[41]. Moket al. analyzed the relevant literature and argued that OS may not differ between EGFR-TKIs as the firstline or second-line therapy, but that this treatment strategy can prolong the mPFS and delay the time of radiotherapy as a first-line treatment to improve patients' quality of life [42]. In the current study, the efficacy of TKI maintenance treatment in patients did not differ significantly from that of chemotherapy plus bevacizumab, even in patients with EGFR mutation. However, further studies are needed before a conclusion can be drawn, because our current study included only 75 patients who received this treatment.

\section{MATERIALS AND METHODS}

\section{Patients}

A total of 794 NSCLC patients with brain metastasis were treated at Shandong Cancer Hospital \& Institute between January 2013 and January 2015. Eighteen patients were excluded because: i) The pathological type of tumor was not confirmed in 7 patients; ii) EGFR mutation status was unknown in 3 patients, and iii) Survival data were 
not available in 8 patients. Thus, 776 NSCLC patients with brain metastasis were included in this retrospective analysis. Among them, 50 patients were lung squamous cell carcinoma and 726 were adenocarcinoma. There were 416 NSCLC patients with EGFR mutation, whereas 360 patients had wild-type EGFR. In these 416 EGFRmutated NSCLC cases, 232 had Exon 19 deletion mutation, whereas 184 had Exon 21:L858R or L861Q mutations. The treatment regimens included adjuvant chemotherapy or chemotherapy plus the targeted therapy (Table 1). In addition, all 776 patients, except 61 patients who only received supportive care, underwent concurrent radiotherapy (WBRT or SRS). Among the 416 patients with EGFR-mutated NSCLC, 249 were treated with chemotherapy alone, 22 with supportive care, 75 with TKIs alone, and 70 with adjuvant chemotherapy plus bevacizumab treatment, including a pemetrexed regimen $(n=37)$ or a taxane regimen $(n=33)$. All the first-line chemotherapy were basis of platinum compounds, and pemetrexed only for these patients. There were also 93 cases with $\mathrm{PS} \geq 3$ received different regimens of treatment and these patients had a strong demand for more treatment; thus, we also included them in this retrospective analysis. Among the 360 patients with wild-type EGFR, 274 were treated with chemotherapy alone, 39 with supportive care, and 47 with adjuvant chemotherapy plus bevacizumab treatment. This study was approved by the Ethics Committee of Shandong Cancer Hospital \& Institute (Shandong, China). The patients or their guardians signed an inform consent form before participation in this study.

\section{Data collection and evaluation criteria}

We collected data regarding all clinicopathological characteristics, treatment responses, and survival from patients' medical records. The treatment responses were evaluated based on the RECIST 1.1 guidelines and classified as complete response (CR), partial response (PR), stable disease (SD), and progression of disease (PD). $\mathrm{CR}$ and $\mathrm{PR}$ were included in the RR, whereas $\mathrm{CR}, \mathrm{PR}$, and SD were included in the disease control rate (DCR). Moreover, all 776 patients were followed up for a median duration of 11.2 months, and the last follow-up date was in May 2015. Survival data were collected through an active follow-up based on the verification of the vital status of these patients. OS was defined as the time from the date patients received the first-line chemotherapy to death or last follow-up, whereas PFS was defined as the time from the date patients received the first-line chemotherapy to disease progression or death. During the follow-up period, 773 patients developed distant metastasis or local recurrence or died of the disease.

\section{Statistics analysis}

All statistical analyses were performed using the Statistical Package for the Social Sciences version 17.0 software (SPSS Inc., Chicago, IL, USA). RRs among these patients were compared and analyzed using the $\chi^{2}$ test, and Fisher's exact test was performed to analyze categorical variables. The Cox regression model was used to identify independent prognostic factors for NSCLC. MPFS and mOS were calculated using the Kaplan-Meier curves and statistically analyzed using the log-rank test. Two-sided $p$ values $\leq 0.05$ were considered statistically significant.

\section{CONFLICTS OF INTEREST}

The authors declare that there is no conflict of interest in this work.

\section{REFERENCES}

1. Jemal A, Bray F, Center MM, Ferlay J, Ward E, Forman D. Global cancer statistics. CA Cancer J Clin. 2011; 61:69-90. doi:10.3322/caac.20107.

2. Eichler AF, Loeffler JS. Multidisciplinary management of brain metastases. Oncologist. 2007; 12:884-98. doi:10.1634/theoncologist.12-7-884.

3. Langer CJ, Mehta MP. Current management of brain metastases, with a focus on systemic options. J Clin Oncol. 2005; 23: 6207-19. doi:10.1200/jco.2005.03.145.

4. Huang Q, Ouyang X. Predictive biochemical-markers for the development of brain metastases from lung cancer: clinical evidence and future directions. Cancer Epidemiol. 2013; 37:703-7. doi:10.1016/j.canep.2013.06.003.

5. Tsao MN, Lloyd N, Wong RK, Chow E, Rakovitch E, Laperriere N, Xu W, Sahgal A. Whole brain radiotherapy for the treatment of newly diagnosed multiple brain metastases. Cochrane Database Syst Rev. 2012; 4: Cd003869. doi:10.1002/14651858.CD003869.pub3.

6. Kondziolka D, Shin SM, Brunswick A, Kim I, Silverman JS. The biology of radiosurgery and its clinical applications for brain tumors. Neuro Oncol. 2015; 17:29-44. doi:10.1093/ neuonc/nou 284 .

7. Ma L, Nichol A, Hossain S, Wang B, Petti P, Vellani R, Higby C, Ahmad S, Barani I, Shrieve DC, Larson DA, Sahgal A. Variable dose interplay effects across radiosurgical apparatus in treating multiple brain metastases. Int J Comput Assist Radiol Surg. 2014. doi:10.1007/s11548014-1001-4.

8. Chang WS, Kim HY, Chang JW, Park YG, Chang JH. Analysis of radiosurgical results in patients with brain metastases according to the number of brain lesions: is stereotactic radiosurgery effective for multiple brain metastases? J Neurosurg. 2010; 113:73-8.

9. D'Ambrosio AL, DeYoung C, Isaacson SR. Radiosurgical management of brain metastases. Neurosurg Clin N Am. 2011; 22:45-51, vi. doi:10.1016/j.nec.2010.08.002.

10. Gaspar LE, Mehta MP, Patchell RA, Burri SH, Robinson PD, Morris RE, Ammirati M, Andrews DW, Asher AL, Cobbs CS, Kondziolka D, Linskey ME, Loeffler JS, et al. The role 
of whole brain radiation therapy in the management of newly diagnosed brain metastases: a systematic review and evidence-based clinical practice guideline. J Neurooncol. 2010; 96:17-32. doi:10.1007/s11060-009-0060-9.

11. Arrieta O, Villarreal-Garza C, Zamora J, Blake-Cerda M, de la Mata MD, Zavala DG, Muniz-Hernandez S, de la Garza J. Long-term survival in patients with non-small cell lung cancer and synchronous brain metastasis treated with whole-brain radiotherapy and thoracic chemoradiation. Radiat Oncol. 2011; 6:166. doi:10.1186/1748-717x-6-166.

12. Bearz A, Garassino I, Tiseo M, Caffo O, Soto-Parra H, Boccalon M, Talamini R, Santoro A, Bartolotti M, Murgia V, Berretta M, Tirelli U. Activity of Pemetrexed on brain metastases from Non-Small Cell Lung Cancer. Lung Cancer. 2010; 68:264-8. doi:10.1016/j.lungcan.2009.06.018.

13. Raizer JJ, Rademaker A, Evens AM, Rice L, Schwartz M, Chandler JP, Getch CC, Tellez C, Grimm SA. Pemetrexed in the treatment of relapsed/refractory primary central nervous system lymphoma. Cancer. 2012; 118:3743-8. doi:10.1002/ cncr.26709.

14. Dai H, Chen Y, Elmquist WF. Distribution of the novel antifolate pemetrexed to the brain. J Pharmacol Exp Ther. 2005; 315:222-9. doi:10.1124/jpet.105.090043.

15. Socinski MA, Langer CJ, Huang JE, Kolb MM, Compton P, Wang L, Akerley W. Safety of bevacizumab in patients with non-small-cell lung cancer and brain metastases. J Clin Oncol. 2009; 27:5255-61. doi:10.1200/jco.2009.22.0616.

16. Sandler A, Gray R, Perry MC, Brahmer J, Schiller JH, Dowlati A, Lilenbaum R, Johnson DH. Paclitaxelcarboplatin alone or with bevacizumab for non-smallcell lung cancer. N Engl J Med. 2006; 355:2542-50. doi:10.1056/NEJMoa061884.

17. Sgambato A, Casaluce F, Maione P, Rossi A, Ciardiello F, Gridelli C. Cetuximab in advanced non-small cell lung cancer (NSCLC): the showdown? J Thorac Dis. 2014; 6:578-80. doi:10.3978/j.issn.2072-1439.2014.06.14.

18. Fidler IJ. Antivascular therapy of cancer metastasis. J Surg Oncol. 2006; 94:178-80. doi:10.1002/jso.20380.

19. Gordon MS, Margolin K, Talpaz M, Sledge GW, Jr., Holmgren E, Benjamin R, Stalter S, Shak S, Adelman D. Phase I safety and pharmacokinetic study of recombinant human anti-vascular endothelial growth factor in patients with advanced cancer. J Clin Oncol. 2001; 19:843-50.

20. Wu YL, Chu DT, Han B, Liu X, Zhang L, Zhou C, Liao M, Mok T, Jiang H, Duffield E, Fukuoka M. Phase III, randomized, open-label, first-line study in Asia of gefitinib versus carboplatin/paclitaxel in clinically selected patients with advanced non-small-cell lung cancer: evaluation of patients recruited from mainland China. Asia Pac J Clin Oncol. 2012; 8:232-43. doi:10.1111/j.17437563.2012.01518.x.

21. Fukuoka M, Wu YL, Thongprasert S, Sunpaweravong P, Leong SS, Sriuranpong V, Chao TY, Nakagawa K, Chu DT, Saijo N, Duffield EL, Rukazenkov Y, Speake G, et al.
Biomarker analyses and final overall survival results from a phase III, randomized, open-label, first-line study of gefitinib versus carboplatin/paclitaxel in clinically selected patients with advanced non-small-cell lung cancer in Asia (IPASS). J Clin Oncol. 2011; 29:2866-74. doi:10.1200/ jco.2010.33.4235.

22. Lee YJ, Park IK, Park MS, Choi HJ, Cho BC, Chung KY, Kim SK, Chang J, Moon JW, Kim H, Choi SH, Kim JH. Activating mutations within the EGFR kinase domain: a molecular predictor of disease-free survival in resected pulmonary adenocarcinoma. J Cancer Res Clin Oncol. 2009; 135:1647-54. doi:10.1007/s00432-009-0611-7.

23. Mitsudomi T, Morita S, Yatabe Y, Negoro S, Okamoto I, Tsurutani J, Seto T, Satouchi M, Tada H, Hirashima T, Asami K, Katakami N, Takada M, et al. Gefitinib versus cisplatin plus docetaxel in patients with non-small-cell lung cancer harbouring mutations of the epidermal growth factor receptor (WJTOG3405): an open label, randomised phase 3 trial. Lancet Oncol. 2010; 11:121-8. doi:10.1016/s14702045(09)70364-x.

24. Mitsudomi T, Morita S, Yatabe Y, Negoro S, Okamoto I, Seto T, Satouchi M, Tada H, Hirashima T, Asami K. Updated overall survival results of WJTOG 3405, a randomized phase III trial comparing gefitinib $(\mathrm{G})$ with cisplatin plus docetaxel (CD) as the first-line treatment for patients with non-small cell lung cancer harboring mutations of the epidermal growth factor receptor (EGFR). J Clin Oncol: Amer Soc Clin Oncol 2012; 30.

25. Zhou C, Wu YL, Chen G, Feng J, Liu XQ, Wang C, Zhang S, Wang J, Zhou S, Ren S, Lu S, Zhang L, Hu C, et al. Erlotinib versus chemotherapy as first-line treatment for patients with advanced EGFR mutation-positive non-smallcell lung cancer (OPTIMAL, CTONG-0802): a multicentre, open-label, randomised, phase 3 study. Lancet Oncol. 2011; 12:735-42. doi:10.1016/s1470-2045(11)70184-x.

26. Rosell R, Carcereny E, Gervais R, Vergnenegre A, Massuti B, Felip E, Palmero R, Garcia-Gomez R, Pallares C, Sanchez J. Spanish Lung Cancer Group in collaboration with Groupe Français de Pneumo-Cancérologie and Associazione Italiana Oncologia Toracica. Erlotinib versus standard chemotherapy as first-line treatment for European patients with advanced EGFR mutation-positive non-smallcell lung cancer (EURTAC): a multicentre, open-label, randomised phase 3 trial. Lancet Oncol. 2012; 13:239-46.

27. Inoue A, Kobayashi K, Maemondo M, Sugawara S, Oizumi S, Isobe H, Gemma A, Harada M, Yoshizawa H, Kinoshita I. Updated overall survival results from a randomized phase III trial comparing gefitinib with carboplatin-paclitaxel for chemo-naïve non-small cell lung cancer with sensitive EGFR gene mutations (NEJ002). Annals of oncology. 2012:mds214.

28. Sequist LV, Yang JC-H, Yamamoto N, O'Byrne K, Hirsh V, Mok T, Geater SL, Orlov S, Tsai C-M, Boyer M. Phase III study of afatinib or cisplatin plus pemetrexed in patients with metastatic lung adenocarcinoma with EGFR mutations. Journal of Clinical Oncology. 2013; 31:3327-34. 
29. Wu Y-L, Zhou C, Hu C-P, Feng J, Lu S, Huang Y, Li W, Hou M, Shi JH, Lee KY. Afatinib versus cisplatin plus gemcitabine for first-line treatment of Asian patients with advanced non-small-cell lung cancer harbouring EGFR mutations (LUX-Lung 6): an open-label, randomised phase 3 trial. The lancet oncology. 2014; 15:213-22.

30. Yang JC-H, Wu Y-L, Schuler M, Sebastian M, Popat S, Yamamoto N, Zhou C, Hu C-P, O'Byrne K, Feng J. Afatinib versus cisplatin-based chemotherapy for EGFR mutation-positive lung adenocarcinoma (LUX-Lung 3 and LUX-Lung 6): analysis of overall survival data from two randomised, phase 3 trials. The Lancet Oncology. 2015; 16:141-51.

31. Fokas E, Steinbach JP, Rödel C. Biology of brain metastases and novel targeted therapies: Time to translate the research. Biochimica et Biophysica Acta (BBA)-Reviews on Cancer. 2013; 1835:61-75.

32. Kienast Y, von Baumgarten L, Fuhrmann M, Klinkert WE, Goldbrunner R, Herms J, Winkler F. Real-time imaging reveals the single steps of brain metastasis formation. Nature medicine. 2010; 16:116-22.

33. Burger RA, Sill MW, Monk BJ, Greer BE, Sorosky JI. Phase II trial of bevacizumab in persistent or recurrent epithelial ovarian cancer or primary peritoneal cancer: a Gynecologic Oncology Group Study. Journal of Clinical Oncology. 2007; 25:5165-5171.

34. Johnson DH, Fehrenbacher L, Novotny WF, Herbst RS, Nemunaitis JJ, Jablons DM, Langer CJ, DeVore RF, 3rd, Gaudreault J, Damico LA, Holmgren E, Kabbinavar F. Randomized phase II trial comparing bevacizumab plus carboplatin and paclitaxel with carboplatin and paclitaxel alone in previously untreated locally advanced or metastatic non-small-cell lung cancer. J Clin Oncol. 2004; 22:2184-91. doi:10.1200/jco.2004.11.022.

35. Bart J, Groen HJ, Hendrikse NH, van der Graaf WT, Vaalburg W, de Vries EG. The blood-brain barrier and oncology: new insights into function and modulation. Cancer Treat Rev. 2000; 26:449-62. doi:10.1053/ ctrv.2000.0194.
36. Shih C, Chen VJ, Gossett LS, Gates SB, MacKellar WC, Habeck LL, Shackelford KA, Mendelsohn LG, Soose DJ, Patel VF, Andis SL, Bewley JR, Rayl EA, et al. LY231514, a pyrrolo [2, 3-d]pyrimidine-based antifolate that inhibits multiple folate-requiring enzymes. Cancer Res. 1997; 57:1116-23.

37. Shih C, Habeck LL, Mendelsohn LG, Chen VJ, Schultz RM. Multiple folate enzyme inhibition: mechanism of a novel pyrrolopyrimidine-based antifolate LY231514 (MTA). Adv Enzyme Regul. 1998; 38:135-52.

38. Adjei AA. Pemetrexed: a multitargeted antifolate agent with promising activity in solid tumors. Ann Oncol. 2000; 11:1335-41.

39. Welsh JW, Komaki R, Amini A, Munsell MF, Unger W, Allen PK, Chang JY, Wefel JS, McGovern SL, Garland LL, Chen SS, Holt J, Liao Z, et al. Phase II trial of erlotinib plus concurrent whole-brain radiation therapy for patients with brain metastases from non-small-cell lung cancer. J Clin Oncol. 2013; 31:895-902. doi:10.1200/jco.2011.40.1174.

40. Lind JS, Lagerwaard FJ, Smit EF, Senan S. Phase I study of concurrent whole brain radiotherapy and erlotinib for multiple brain metastases from non-small-cell lung cancer. Int J Radiat Oncol Biol Phys. 2009; 74:1391-6. doi:10.1016/j.ijrobp.2008.10.026.

41. Kim JE, Lee DH, Choi Y, Yoon DH, Kim SW, Suh C, Lee JS. Epidermal growth factor receptor tyrosine kinase inhibitors as a first-line therapy for never-smokers with adenocarcinoma of the lung having asymptomatic synchronous brain metastasis. Lung Cancer. 2009; 65:351-4. doi:10.1016/j.lungcan.2008.12.011.

42. Mok T, Yang JJ, Lam KC. Treating patients with EGFRsensitizing mutations: first line or second line - is there a difference? J Clin Oncol. 2013; 31:1081-8. doi:10.1200/ jco.2012.43.0652. 